\title{
Formação de Professores e Reformas Curriculares: Entre Projeções e Normatividade
}

\author{
Geniana Santos \\ Secretaria do Estado de Educação de Mato Grosso (SEDUC), Centro Uni- \\ versitário de Várzea Grande, UNIVAG-MT, Brasil \\ Veronica Borges \\ Universidade do Estado do Rio de Janeiro, UERJ, Brasil \\ Alice Casimiro Lopes \\ Universidade do Estado do Rio de Janeiro, UERJ, Brasil
}

\section{Resumo}

Neste texto, objetivamos desestabilizar a significação essencializada para a identidade do/da professor/a, bem como questionar a responsabilização/culpabilização docente pelos resultados da escolarização nas políticas para a formação de professores. Recorremos à teoria do discurso (TD), de Laclau \& Mouffe, e à perspectiva discursiva das políticas curriculares, desenvolvida por Lopes \& Macedo no Brasil. Defendemos que os projetos de futuro para a formação de professores, em um cenário delineado pela crise educacional e pelo risco à democracia, vêm produzindo sentidos horríficos e beatíficos no âmbito das políticas educacionais. As matrizes de substituição da ordem e do reconhecimento, ou seja, na ordem da economia, quer seja da família, da escola, da justiça, precipitam, na radical contingência, que a decisão seja assumida pelos sujeitos menos pelo rationale que possa comportar e mais pela radical indecidibilidade constitutiva da responsabilidade - marcada pela ausência de certezas e pela urgência da decisão/autoria.

Palavras-chave: Política de currículo. Formação docente. Teoria do discurso. Responsabilidade.

\section{Abstract}

In this paper, we aim to destabilize the essentialized meaning for the teacher identity, as well as to question the accountability/culpability of teachers for the results of schooling in the policies for teacher education. We operate with the theory of discourse (TD), of Laclau \& Mouffe, and with the discursive perspective of curriculum policies, developed by Lopes \& Macedo in Brazil. We argue that projects for the future of teacher education, in a scenario outlined by the educational crisis and the risk to 
democracy, have been producing horrific and beatifical meanings for the scope of educational policies. The substitution matrices of the order and the recognition, i.e. in the order of the economy, whether it is family, school, justice, precipitate in the radical contingency that the decision is assumed by the subjects less by the rationale that may behave, and more by the radical undecidability constitutive of responsibility - marked by the absence of certainties and the urgency of the decision/authoring.

Keywords: Curriculum policy. Teacher training. Theory of discourse. Responsibility.

\section{Introdução - situando a problemática}

Este trabalho mobiliza o campo das políticas curriculares para formação docente com a pretensão de abalar proposições ditas reformadoras que, em seu nome, em nome da transformação das relações educacionais (entendida por muitos como necessária), projetam e normatizam a atuação docente via política.

A noção de currículo orientadora desta discussão se ancora em Lopes (2006, 2014, 2015, 2018), Lopes e Macedo (2011) e Macedo (2006, 2015), especialmente no tocante à definição de currículo como ficção, como texto, como construção discursiva e prática de significação, espaço de disputa e negociação de sentidos. Isso conota que o currículo, sempre elusivo, é marcado simultaneamente pela tradição e pela ressignificação, sendo a política de currículo uma expressão da luta por fixação de sentido, subjetivação e endereçamento de identidades, dentre elas a própria identidade do que vem a ser currículo.

Destacamos o entendimento de negociação como algo que supera a simplificação da noção de política como ato situado no que convencionalmente é definido como espaço oficial, por vezes governamental, de processos decisórios. Entendemos, a partir da perspectiva discursiva, que todos os espaços de vida são políticos - e potencialmente democráticos - e operam em diferentes relações de poder com a abertura para a negociação conflituosa de sentidos. A intersecção entre essas duas compreensões permite investigar a política curricular para além de atos mandatórios, regulatórios e normativos, dispostos por meio de documentos oficiais, incluindo, assim, ações/decisões deliberadas a partir da razoabilidade, pautadas também nos contextos convencionalmente definidos como da prática educacional e do pensamento curricular.

Em tempos em que mais um ciclo de reformas curriculares se evidencia com vistas a um suposto avanço educacional, usualmente lido como ampliação da qualidade da educação, mostra-se pertinente problematizar as projeções de identidades, especialmente nos processos de formação inicial e continuada, uma vez que tais projeções surgem como resposta a um discurso de falha generalizada da docência, da crise educacional e de culpabilização docente. 
Acerca das modificações da organização curricular, a década de 1990 foi um período de conturbada produção discursiva. Diferentes textos tratavam da necessidade de reformulação a partir do discurso de falta de qualidade no cenário educacional brasileiro. Há ampla discussão sobre a estruturação de um pensamento curricular brasileiro para o mesmo período, focalizando os discursos de crise educacional em uma esfera global, conforme evidenciado por meio de traduções de textos de curriculistas estrangeiros (Macedo, 2006).

Pesquisas evidenciam que as reformas sedimentam discursos que circulam, em grande medida, na área das políticas educacionais fortalecidos pelos campos da avaliação imbricados ao campo dos negócios (Ball, 2004, 2010, 2012, 2014; Ravitch, 2011). Neste imbricamento, identificamos a crescente vinculação (estreita e direta) entre currículo, avaliação e formação docente. O contato com a linguagem do mercado é recorrente, e como efeito, temos as políticas meritocráticas. O objetivo dessas políticas é o cumprimento de metas previamente dadas com a responsabilização dos atores e dos processos. Nessas políticas, opera-se a partir da lógica dos resultados obtidos via mensuração e rankeamento institucional. Vale destacar que esses discursos se estabelecem em níveis global e local, não se instituem somente na realidade brasileira, mas são expressos de forma conectada às ações e agendas de países signatários, visando a um projeto de sujeito global, competente, pacificado, pró-ativo e competitivo.

São discursos reformadores que, nas últimas décadas, colocam como desafios a superação desse cenário via política de accountabillity. Esta política é ancorada em relações de causa e efeito: aprimoramento da avaliação visando à produção de resultados objetivos capazes de identificar e responsabilizar atores e seus processos de ensinar. Sendo assim, a formação de professores tem sido um dos alvos preferenciais dessas políticas. Conforme Dias Sobrinho (2003), a compreensão de que os educadores são prestadores de serviços e, portanto, "devem prestar conta ante os usuários" é característico desse modelo de avaliação centrado nos vínculos entre custo e benefício dos investimentos realizados em educação. Ainda para esse autor, “(...) não se tratava mais simplesmente de avaliar alunos, mas também os professores, as escolas, os conteúdos, as metodologias e estratégias de ensino etc." (Dias Sobrinho, 2003, p. 22).

Os resultados obtidos, os escores insuficientes, em geral, mais do que contextualizar vias de intervenção, apontam para o déficit formativo daqueles que deveriam ensinar, desconsiderando outras variáveis importantes do processo educativo, como infraestrutura, nível socioeconômico, descompasso ou dificuldade de definir o que deve ser avaliado e como dever ser avaliado, (in)compreensões sobre o que se entende por currículo, avaliação, conhecimento, dentre outros elementos do cenário educacional. É usual a afirmação de que a melhoria da qualidade da educação pode vir a ampliar as possibilidades de trabalho e renda e as condições de vida das pessoas. Dificilmente, contudo, se destaca como o inverso é igualmente verdadeiro: mais e melhor se estuda e aprende quanto melhores forem as condições de vida das famílias 
dos estudantes ${ }^{1}$.

A reflexão sobre os resultados da mensuração da aprendizagem, em um recorte de tempo específico, é outra questão sensível nesse cenário. Pois, quando escrutinamos os sentidos da proficiência na aprendizagem de crianças ou de adultos, identificamos que proficiência nem sempre traduz a aprendizagem, mas sim, a competência em responder a itens conforme solicitado em um determinado exame. $\mathrm{O}$ que dizer, por exemplo, de uma avaliação como a ANA (Avaliação Nacional da Alfabetização), que destaca a alta proficiência em escrita em determinada região do país, como é o caso de Mato Grosso, ultrapassando a média brasileira em escrita, mas apresentando igualmente insuficiência em leitura? Como ler resultados discrepantes entre leitura, escrita e matemática? Tais casos são possíveis de serem verificados nos resultados das Avaliações realizadas em 2014, como discutido em Santos \& Couto (2018). Para além de pensar a partir da polarização entre proficiente e não proficiente, consideramos que seria mais producente compreender quais práticas de ensino promovem a ilusão de aprendizagem no quesito escrita, automatizando os processos de ensinoaprendizagem, tais como o foco na repetição e prática copista, talvez estimulados pelos próprios resultados de avaliação externa.

Neste trabalho, a partir dessas reflexões, propomos então discutir o processo de responsabilização docente em um cenário de contínuas reformas curriculares, delineando os impactos para a formação de professores e para o futuro da docência brasileira.

\section{Perspectiva discursiva como aporte teórico-estratégico}

Ainda que o debate ora empreendido se circunscreva ao campo da educação, mais especificamente da política curricular de formação de professores, destacamos o caráter político em sua radical contingência a partir de uma perspectiva discursiva que envolve toda e qualquer política. Para tal, o aporte teórico-estratégico orientador desta investigação recorre aos pressupostos da teoria do discurso (TD), de Ernesto Laclau e Chantal Mouffe (2011), e da perspectiva discursiva para a compreensão das Políticas Curriculares desenvolvida por Lopes \& Macedo (2011).

No que diz respeito às categorias teóricas deste estudo, trabalhamos com as noções de contingência e responsabilidade, bem como de responsabilização docente. As duas primeiras noções estão relacionadas ao arcabouço teórico da TD e a terceira encontra-se no horizonte das perspectivas críticas. Em nosso entendimento, a responsabilização circunscreve o debate pelo reconhecimento de que as estruturas

$1 \quad$ Apenas a título de exemplo, estudo do Instituto Trata Brasil, formado por empresas interessadas na ampliação do saneamento básico no país, realizou estudo que aponta a correlação entre o absenteísmo escolar, o índice de reprovação e o baixo aproveitamento escolar são maiores nas regiões em que as crianças moram em casas sem saneamento básico.

http://www.tratabrasil.org.br/blog/2008/09/01/saneamento-basico-e-educacao/ Acessado em 07 de março de 2019, às 09:24 h. 
econômicas ditam os princípios das políticas e que a saída para uma crise de valores passa pela superação dessa lógica rumo a uma sociedade na qual a luta de classes e a exploração econômica não encontrem espaço.

Tendo em vista o aporte teórico-estratégico ao qual nos vinculamos, impõe-se uma reconfiguração nos modos como tais questões são colocadas. Enfatizamos os posicionamentos não dicotômicos e não essencialistas que se afastam, em grande medida, das mais diversas teorias sociológicas, quer sejam as que visam à emancipação, quer sejam as que focalizam a resistência. Ao acompanharmos os teóricos da TD em sua compreensão de que as estruturas são descentradas e não fixas, defendemos que qualquer ordem social se inscreve e se constitui por relações de hegemonia provisórias e precárias. Decorre disso que a sociedade não pode ser entendida como se fosse um todo estruturado e calcado em posições fixas dos sujeitos. Decorre também que essa representação da sociedade, da educação, dos sujeitos, afasta-se de um ideário clássico de representação caracterizado pelo espelhamento entre o representante e aquilo que é representado, com fortes tendências de que haja correlação estreita entre eles. A partir da perspectiva discursiva, a noção de representação opera com o particular e o universal como mutuamente constituídos, sendo ambos marcados pela incompletude constitutiva da significação (Laclau, 2011a). Assim, compreendemos que as políticas curriculares reverberam as disputas políticas pela significação do que seja mundo - do que seja sociedade, democracia, emancipação, resistência, equidade social, responsabilidade social, entre tantas outras demandas por significação.

Com isso ressaltamos a incapacidade de regulação total: os sentidos sempre irrompem. É impossível o controle absoluto via responsabilização e é neste aspecto que fazemos a crítica à resistência ao poder ou à emancipação, problematizando que há ambivalências inscritas nessas relações. "Que dizer sobre a representabilidade?", indaga Ernesto Laclau (2011a, p.154):

É claro que, se não há qualquer fundamento racional último do social, a representabilidade total é impossível. Mas, nesse caso, poderíamos falar de representações "parciais", as quais seriam, dentro de seus limites, imagens mais ou menos adequadas do mundo. Se o terreno do fundamento for ocupado por uma contingência radical, todo sentido social será uma construção social, e não um reflexo intelectual do que sejam as coisas "em si mesmas". A consequência é que, nessa "guerra de interpretações", o poder, longe de ser meramente aparente [appariential], faz-se constitutivo da objetividade do social.

A aposta que nos mobiliza está, portanto, amparada na condição de mobilizar redescrições mais amplas que sejam operadas para além da ideia de substituição de uma lógica por outra - como na representação clássica. Para tal, destacamos como determinadas inteligibilidades viabilizam/pavimentam a via de certas demandas e projetos de futuro para a formação de professores. Em um cenário delineado pela crise educacional e pelo risco à democracia, garante-se sentidos horríficos e beatíficos para o âmbito das políticas educacionais. Consideramos que as políticas curriculares carreiam certos sentidos que estão sendo consensuados no campo falta de qualidade da educação e má formação dos professores -, formalizando um 
discurso de denúncia ao mesmo tempo propulsor de mudanças no social que atuam em registros discursivos muito próximos daqueles a que se arvoram combater. A seguir, reafirmando a problematização de que as políticas (educacionais, curriculares) possam estar contidas em uma superestrutura e nesse mesmo movimento, inscrevendo-as em um terreno indecidível, colocamos em marcha possíveis deslocamentos de sentidos no campo da formação de professores.

\section{Formação de professores em contextos reformistas}

O contexto reformista se mostra como via de construção social, a partir da Segunda Guerra Mundial, por meio do projeto humanístico instaurado e objetivado nos "trinta gloriosos", em que as sociedades ditas desenvolvidas delinearam uma forma de construção do humano em face da ameaça de barbárie, expressa pela experiência do Holocausto.

Após esse período, e com a crença de que o desenvolvimento econômico e educacional deveria estar imbricado à construção de uma sociedade livre, humana e humanizadora, é possivel notar diferentes investidas com vistas a reformar a educação, e por meio dela o sujeito, para que fosse possível alcançar a sociedade do bem-estar social.

É nesse cenário que tanto a formação inicial como a formação continuada dos professores passaram a ser regularmente assinaladas como campos diretamente ligados à defesa de que determinadas instituições precisam responder às demandas da sociedade por uma educação de qualidade para todos. Os sentidos de qualidade postos em questão, entretanto, são ancorados em proficiência e resposta adequada ao item avaliado, algo que não corrobora com uma discussão mais ampla sobre a aprendizagem dos estudantes.

Conforme Gimeno Sacristan (1994, p. 15-16),

A avaliação se tornou um instrumento para diagnosticar quantitativamente a rentabilidade e a eficiência da escola, dos processos pedagógicos e administrativos. Com esse fim, dedicouse a elaborar instrumentos adequados a esses diagnósticos, selecionar instrumentos de êxito, como por exemplo, tempo para execução de uma tarefa, porcentagem de sucesso na escolarização, número de alunos aprovados nos diversos níveis, e a formular índices para "diagnosticar o êxito da empresa escolar.

Além disso, segue dizendo Gimeno Sacristan (1994), a avaliação se tornou a prova mais contundente e irrefutável para assegurar a necessária reforma educacional, realizada de tempos em tempos, como meio de afastar a proeminente ameaça ao social. A conexão entre avaliação e reforma, desse modo, se mostra retroalimentada pelos indicadores de qualidade, eficiência e eficácia, custo/benefício dos investimentos educacionais. 
Entre os dispositivos que estamos considerando como pautados por reformas estão os textos políticos, aqui compreendidos como práticas discursivas, mas não somente eles. As políticas (textos, cursos, avaliações, materiais didáticos etc.) não se furtam em definir como tarefa principal a construção de estratégias que visem a formar os professores via "novas técnicas", "melhores práticas", "aprendizagem ativa", "a aprendizagem cooperativa" e outras ações semelhantes, conforme Andy Hargreaves (1999) aponta em sua análise sobre as mudanças do professorado. Consideramos ainda atuais as ponderações do autor com relação à orquestração de demandas com vistas a alcançarem a educação como um todo e aos docentes e suas práticas em particular:

La gente pretende siempre que cambien los professores. Es difícil encontrar um momento em el que esta afirmación haya tenido más vigencia que em los últimos años. Esta época de competitividade global, como todos los momentos de crisis económica, está produciendo um pánico moral inmenso ante la forma de preparar a las generaciones del futuro em nuestras respectivas naciones. Em momentos como éstos, la educación em general y las escuelas em particular se convierten em lo que A. H. Halsey llamó una vez "la papelera de la sociedade": receptáculos políticos em los que se deposita sin ceremonia alguna lo no resuelto de la sociedade y los problemas insolubles. Pocas personas desean hacer algo respecto a la economia, pero todo el mundo - políticos, medios de comunicación y público en general - quieren hacer algo com la educación." (Hargreaves, 1999, p. 31).

Tanto teóricos do campo da formação docente (Hargreaves, 1999; Labaree, 1998) quanto os do campo das políticas educacionais, em diferentes âmbitos (Afonso, 2009, 2013, 2014; Brooke, 2006, 2013, 2008; Freitas, 2014; Ravitch, 2011), assumem haver a centralidade da agenda da mudança, a partir de políticas de accountability (prestação de contas, responsabilização) que se impõem como um discurso hegemônico.

Com isso, constatamos que o terreno educacional é um território disputado por vários segmentos da sociedade e não identificamos, no campo educacional, no que denominamos modernidade, espaços/tempos de ensinar/aprender que não estejam marcados/afetados pelo teste ou pela avaliação. Os sentidos nunca são os mesmos, mas há diferentes tentativas de definir práticas educativas por meio de objetivos/ descritores previamente definidos e resultados de aprendizagem previamente projetados e vinculados a determinados fins. E isso, em geral, se dá "em nome de algo", em nome de um "demos a ser garantido" (Brown, 2015).

\section{Reformar é preciso, educar não é preciso}

Nessa perspectiva, não consideramos como algo fortuito que essa discussão se apresente estreitamente ligada às intensas reformas curriculares que tentam projetar "o que é" ou como "deve ser" a formação docente, como a que ocorre no caso brasileiro nos últimos anos (Base Nacional Comum Curricular, Programa da Residência Pedagógica, Reforma Ensino Médio, dentre outros). Há uma tentativa bastante recorrente visando a determinar um projeto identitário docente a ser alcançado. 
Compreendemos que há, nessas propostas supracitadas, a promessa de redenção que passa pela via do conhecimento, visando ao acúmulo de qualificações com o propósito de certificação, ou seja, de atribuição de valores, com fins de prestar contas à sociedade.

Entendemos que tal promessa está inscrita na lógica da plenitude (lógica que busca alcançar um projeto já dado "como se" fosse o único, o racional e o lógico) e que não se furta de anunciar seu caráter beatífico. No mesmo processo é afirmado também o caráter horrífico daquilo que deve ser evitado, afastado enquanto ameaça, discussão fomentada por Lacan e retomada por Clarke (2015), assim como Santos (2017).

O caráter horrífico delineia a crise como aquela que ameaça a possibilidade de a escola, por meio do ensino, formar um sujeito capaz de modificar a realidade social presente, mas também se conformar a ela (sua estrutura econômica, ideológica). Ao reiterar uma designação horrífica para sua ausência/seu fracasso no ambiente escolar, significa a aprendizagem, sua ausência como algo catastrófico, capaz de, inclusive, comprometer a existência humana. Ainda nesse entendimento, esse discurso horrífico, pautado em uma dimensão mítica (Laclau, 2006), necessita de uma estrutura que se configura como promessa de salvação para o estudante, para a escola e, por conseguinte, em uma relação determinista e sem mediações, para o social.

Em face do discurso horrífico, emergem promessas de salvação. Por isso, tanto o horror quanto a salvação são elementos antagônicos, polarizados, mas que estão conectados por uma mesma lógica. O caráter salvífico e beatífico que a aprendizagem encarna a centraliza como meio, instrumento para a formação de um humano pacífico, crítico e cidadão. É suposto que, sem isso, apenas o horror prevaleceria.

Outro elemento para adensar tal discussão é a articulação discursiva que se alimenta, em grande medida, da busca de um canal de controle dos processos de ensinar e aprender. As práticas discursivas reformistas operam, conectadas à avaliação, em um discurso em que a aprendizagem está ausente, devido ao trabalho deficitário do professor. Por isso, tais práticas, em um intervalo de pouco mais de vinte anos, ganham destaque em sua absoluta condição de política necessária para enfrentar a ameaça ao futuro social.

Essa reflexão incide em levantar como a responsabilização docente tem sido pautada nas políticas, tanto no cenário local quanto global, por princípios ditos neoliberais que, na educação, focalizam o acúmulo de conhecimento e qualificações a partir do modelo econômico que opera com a noção de acúmulo de lucro e mercadoria, por exemplo. Esse conhecimento é mensurado por critérios legitimados majoritariamente fora do campo educacional com vistas à defesa da clareza e precisão nas formas de avaliar (modelo racional ou científico, conforme Dias Sobrinho, 2003). Tal precisão é a força motriz de um sistema de avaliação eficaz que transforma de modo positivo as respostas obtidas em solução eficiente. 
Vale destacar que nosso argumento não compartilha da convicção de que somente educadores possam ser considerados os que têm legitimidade para tratar questões do campo da educação como prática social. Ainda assim, nos interessa pôr em discussão como se hegemonizam os projetos de sociedade, de cidadania, de democracia, de políticas educacionais, de políticas de formação docente pautados pelos crivos de áreas como economia ou gestão empresarial em políticas de avaliação. Trata-se de um filtro que atua na cirúrgica individuação dos sujeitos com fins de materializar e produzir respostas no sentido de afastar (excluir, neutralizar) o elemento dissonante do sistema. Esse elemento pode até se configurar, de modo mais amplo, como o modelo de ensino-aprendizagem, dada política curricular ou dado sistema de avaliação. De modo recorrente, entretanto, o alvo a ser atingido tem sido projetado no sujeito que não ensina - o profissional docente: aquele que deve ser controlado para o bem de todos, para o bem da educação de qualidade para todos, com vistas a garantir a democracia via prestação de contas à sociedade e ao mercado.

Embora haja diferentes modelos de accountability que integram, em combinatórias várias, os pilares da avaliação, da prestação de contas e da responsabilização (Afonso, 2010b; Afonso, 2012, o modelo defendido pelas ideologias neoconservadoras e neoliberais (atalmente hegemônicas em muitos países) é essencialmente um modelo misto no qual os diferentes pilares se dividem entre o Estado e a sociedade civil (e, neste último caso, com um apelo mais direcionado ao mercado). (Afonso, 2014, p. 501)

Vale destacar que tal ordenamento discursivo só faz sentido na lógica horrífica e beatífica (ou salvífica), na polarização dos sentidos socialmente construídos que evidenciam a salvação ou a condenação dos sujeitos que preferencialmente escolhem pela própria salvação ou condenação, e, portanto, são responsáveis pela sua própria redenção ou infortúnio. As concepções que alimentam esses modelos operam na busca de dispositivos identitários, que atuem de modo racional, com a finalidade de que determinadas ações conduzam a determinadas respostas. Identificamos que essas lógicas estão, tanto no que se entende como projetos neoliberais, como em uma reapresentação do liberalismo clássico que prevê a liberdade, a autonomia, a regulação pelo mercado, com o apequenamento do Estado. Mas também encontramos as lógicas horrífica e beatífica no legado de perspectivas sociológicas na educação, que se deslocam e atribuem à emancipação, ou a sua carência, o modo capaz de reconfigurar a sociedade. Nesse modelo, há uma ideia progressivista da sociedade em andamento. Esta é uma lógica que projeta o dever ser social a partir de um modelo de sujeito e de sociedade previamente dados.

Para cumprir tal empreitada, consideramos que ambas as lógicas, aqui identificadas como mercadológica ou sociológica, têm como amarras estruturalidades capazes de estabelecer previamente a trajetória a ser trilhada, antecipando as decisões curriculares, bem como as decisões avaliativas a partir de fundamentos e processos identitários que visam a definir o outro - o professor, o aluno - na medida em que definem o saber do outro, o currículo do outro. Objetivamos com tal abordagem desestabilizar a significação essencializada para o docente. Também colocamos em marcha os sentidos de responsabilização docente dada a centralidade/recorrência 
desse significante nas políticas curriculares de formação. Tendo em vista a perspectiva discursiva na qual esta investigação está inserida, vale ressaltar que não nos pautamos na citação explícita do vocábulo responsabilização docente. Consideramos que esses sentidos circulam, quer por bloqueios/omissões ou por ativação de outros significantes como avaliação, prestação de contas, culpabilização, bonificação, entre outros.

\section{Responsabilização docente: projeções e normatividades em marcha}

Estão em marcha sentidos que circulam como responsabilização docente e mobilizam, sobremaneira, os debates do campo da educação como um todo e da formação de professores em particular, assim como os campos de currículo e de políticas educacionais, tanto em nível nacional como em um cenário internacional.

As perspectivas teóricas disputam sentidos de como a qualidade da educação se consolida pautada por perspectivas neoliberais cujo foco está em processos mensuráveis em uma relação causalista entre currículo, avaliação e formação de professores. Cada um desses elos trata o conhecimento como mercadoria a ser selecionada, passivel de aplicação e mensuração por profissionais docentes. Nesta lógica, se a mercadoria conhecimento não circula de acordo com o previsto, cabe identificar o entrave, que de modo reiterado recai no professor, uma vez que os outros aspectos tendem a estar controlados. Sendo assim, estamos diante de uma compreensão de currículo e avaliação como processos controlados.

O elemento que ainda escapa a essas lógicas são os sujeitos do ensinar e aprender. Os processos discursivos que sustentam as políticas curriculares para a formação docente tendem a operar com os discursos identitários que postulam o perfil do professor para a mudança, o perfil do professor que deve atuar como implementador das propostas. Operam identitariamente, colocando o professor como aquele que deve resistir a esse processo de cristalização das relações de aprender/ensinar pautadas pela prestação de contas como se estas proposições estivessem reguladas centralmente por determinações econômicas. Os sentidos que têm tido passagem como senso comum no campo das políticas educacionais se espraiam por eixo discursivo ora denominado "educação gerencialista".

Há um discurso legitimado por uma lógica educacional que indica como tarefa docente alcançar metas que estejam previamente normatizadas e que estejam sendo monitoradas por órgãos reguladores. Diversos autores tratam desta temática no cenário brasileiro (Freitas, 2012, 2013, 2014; Brooke, 2006; Oliveira, 2005), como também internacionalmente (Afonso, 2009, 2013, 2014; Ravitch, 2011; Dias Sobrinho, 2003; Taubman, 2009). Ainda que haja divergências quanto à vinculação entre as políticas da responsabilização docente norte-americanas e as políticas de responsabilização brasileiras (conferir Freitas, 2013), há o reconhecimento de que essa é uma lógica a ser enfrentada no campo, dado o seu caráter insidioso e que se desloca dos âmbitos locais e globais. 
Em geral, o debate no Brasil vai no sentido de crítica e denúncia dessas práticas consideradas meritocráticas, pautadas pelo gerencialismo, reguladoras dos fazeres docentes, que se identificam com os processos de individuação e com a atribuição ao professor da responsabilização (culpabilização dos docentes) por resultados não satisfatórios relativos à proficiência dos estudantes.

Dito de outro modo, são políticas curriculares educacionais (Base Nacional Comum Curricular, Reforma do Ensino Médio, Residência Pedagógica) que centram seu debate na afirmação de que a educação brasileira falha/falhou em não ter respostas satisfatórias às demandas da sociedade. A educação não atende às convocatórias enunciadas pelo mundo do trabalho, por ex. - não consegue entregar sujeitos devidamente preparados para o exercício profissional. Sendo assim, resta identificar o elemento-chave dessa equação e corrigi-lo: as políticas curriculares de formação docente (ou o professor em última instância) sobre as quais recaem os diagnósticos das políticas de avaliação em larga escala.

Nosso interesse é argumentar em torno dos discursos que se articulam, fortalecendo ou bloqueando o que se entende como responsabilização docente. Em uma rápida investigação acerca das políticas de responsabilização, o vernáculo accountability aparece como aquele que carreia sentidos para o campo da educação. Vale pensar como se deu, por exemplo, a passagem de uma ideia de responsabilidade social para responsabilidade educacional. Nesse sentido, cabe ainda questionar, quais sedimentações foram necessárias para promover a passagem de uma visão de responsabilização e prestação de contas com vistas ao bem comum para esquadrinhamentos que localizam em determinados indivíduos o ônus por respostas não satisfatórias em face de mensurações externas. Quais as aderências que tornam possíveis naturalizações do tipo: "o professor não possui formação adequada", "as instituições de formação focalizam a teoria", "o currículo comum é garantia de educação de qualidade a todos", "a ênfase nas melhores práticas em sua condição modelizante da formação em serviço", entre outras expressões de efeito que se propagam nas formações discursivas das políticas de formação docente.

Também importa considerar a centralidade dada a um só aspecto com a secundarização de tantos outros. Encontramos uma forte argumentação pautada por aspectos econômicos, quer seja em nome da evocação da eficiência e eficácia e de binômios como ensinar-avaliar, ora na ênfase de aspectos pedagógico-educacionais como os diferentes movimentos em prol do empreendedorismo, da sociedade da informação, da aprendizagem ao longo da vida ou da sustentabilidade como fatores determinantes na contemporaneidade. Com isso, exploramos como se obliteram dessas discussões o político, o caráter de negociação radical que envolve o político (Mouffe, 2005). Defendemos que essas racionalidades funcionam como se pudessem empurrar o conflito para fora do debate, e, assim, cristalizam as discussões que circulam em torno do imaginário de crise da educação e de que há em curso uma ameaça à democracia. 
Consideramos potente argumentar que discursos gerencialistas - aqueles que, no campo da educação, tratam o conhecimento como mercadoria, como se o conhecimento só tivesse valor por seu acúmulo e pela possibilidade de gerar qualificações garantidoras de formas de melhor gerenciar - e discursos que propõem resistências a tal posicionamento na educação e colocam-se apartados da problemática a ser resolvida.

Tais discursos circunscrevem a problemática em uma estrutura que possui um funcionamento próprio e que aglutina duas lógicas diversas, conflitantes e contraditórias: a lógica do mercado, cuja ênfase está nos fins econômicos, e a lógica social que visa à justiça social. Por meio da clivagem entre essas lógicas, opera-se como se houvesse um ponto de vista econômico, com centralidade nas métricas (avaliar professores e alunos) que possam informar e regulamentar as ações para atingir a propalada "educação de qualidade", e um ponto de vista social, pelo qual há um movimento de rechaço de propostas de avaliação que responsabilizem indivíduos, as ditas políticas de accountability, mas em geral consideram que a avaliação do sistema pode ser uma possibilidade de buscar saídas coletivas para um sistema que tem se mostrado perverso e ineficaz em suas proposições (Bauer, 2012; Freitas, 2014).

Em nome de garantir a educação de qualidade para todos, defende-se que determinada categoria e, ainda mais, que determinados indivíduos possam assumir tais funções horríficas ou beatíficas de acordo com as respostas a serem obtidas. Ambos os pólos, ainda que antagônicos, operam por projeções com a pretensão de hegemonizar seus posicionamentos políticos. O que destacamos dessas análises é que a decisão está tomada fora do conflito, fora do acontecimento, e está sendo, de diferentes modos, inserida em lógicas ditas racionais pelo crivo da metafísica ocidental. Este é o ponto que nos parece importante pôr em questão: como criar condições de empreender o debate no campo da formação docente que inclua o risco (Biesta, 2013) e o caráter impossível do educar (Lopes, Borges, 2015) e ainda assim ser responsável por seu fazer, ser responsável, sobretudo, por aquilo que não se sabe previamente, pela decisão por vir (Derrida, 2006).

A responsabilidade não é algo que possamos institucionalizar e fixar em um lugar no tempo e espaço como, por exemplo, as políticas de responsabilização docente vêm fazendo. Ainda assim, inspira-nos pensar na responsabilidade como algo do qual não há como abrir mão, porque é constitutivo do sujeito. Consideramos como estratégico colocar em marcha sentidos que possibilitem operar com a ideia de uma responsabilidade docente que intervém, que opera disruptivamente, revelando algo inesperado, não antecipado e ignorado.

\section{A urgência da decisão em um cenário de ausência de certezas: a res- ponsabilidade em questão}

A perspectiva discursiva opera em reconfigurações que abalam a visão linear da 
história, o que incide em efeitos políticos. Ademais, enfatizamos com forte inspiração derridiana, via gesto desconstrutivo, que nossa inscrição no mundo emerge nos processos decisórios que entram em cena a partir de matrizes de substituição da ordem e do reconhecimento, ou seja, na ordem da economia, quer seja da família, da escola, da justiça (Derrida, 1994).

As referidas matrizes se inscrevem na radical contingência e precipitam um processo decisório pautado na razoabilidade. Resulta que a decisão seja assumida pelos sujeitos menos pelo rationale que possa comportar, e mais pela radical indecidibilidade constitutiva da responsabilidade - marcada pela ausência de certezas e pela urgência da decisão/autoria.

Cabe trazer aqui que a perspectiva discursiva ora assumida possui também inspiração na psicanálise lacaniana. Por meio dessa inspiração, nossa entrada na ordem simbólica da linguagem como sujeitos nos impõe a perda, a falta (constitutiva) de qualquer senso pré-subjetivo de pertencimento ao mundo.

Entendemos que a necessidade de contínuas reformas curriculares atende a essa pretensão de preenchimento, de estabilização e ordem em resposta a uma demanda sempre urgente, embora nunca satisfeita, mas que necessita continuamente ser ordenada discursivamente para que se tenha um rumo e prumo estruturante ao trajeto.

Somos "linguageiros", não naturais, marcados desde sempre por este alijamento do mundo dito natural. "Seres" que nunca tiveram uma só experiência que possamos afirmar como imediata ou não mediada pela linguagem, não há uma experiência que possa ser considerada como experiência de uma presença (Haddock- Lobo, 2013). Por sermos constituídos na linguagem, estamos alienados do que nos circunda como também estamos desde sempre submetidos ao funcionamento da linguagem. A contingência radical da perspectiva discursiva está marcada por todas as idiossincrasias que constituem os remetimentos de significantes para significantes. O sentido em si não se encontra, os sentidos estão sempre em marcha e operam por contaminação mútua, como defendido por Laclau (1990).

Um significante como democracia, via reforma educacional, encontra-se assim vazio de significação. A fim de que possa articular múltiplas demandas, vários sentidos se equivalem tornando a cadeia discursiva ampla ao ponto de perder qualquer sentido particular e preciso. A tentativa de encontrar o espaçotempo da democracia enquanto tal é sempre tentativa vã. A contingência radical constitutiva do político se apresenta nesse movimento que expulsa sentidos antagônicos (horríficos) para hegemonizar determinado discurso (Laclau, 1990).

O questionamento que aqui se coloca não objetiva desqualificar os posicionamentos críticos e seu movimento de denúncia dos processos instituídos por reificações polarizadas, como também não visa a focalizar o cunho gerencialista que tem deixado 
marcas nos textos curriculares. Operamos nas práticas discursivas em disputa por sentidos e estas disputas alcançam hegemonia na contingência radical. Desse modo é que supomos poder reforçar o caráter político da formação de professores.

\section{Conclusões: precipitações contingentes que se impõem no jogo das disputas por sentidos}

Apresentamos aqui um exercício de pensamento, um gesto talvez, no sentido de colocar sob suspeição os discursos que já são considerados senso comum e que tendem a se colocar como se estivessem fora das práticas discursivas ditas neoliberais e a se vincular aos discursos críticos que denunciam e indicam saídas coletivas/ sociais para a construção de uma boa sociedade ou daquilo que identificamos "boa consciência" com projeto de reconciliação da sociedade/do social.

Nosso intento foi o de problematizar os discursos da responsabilização docente a fim de abalar suas fronteiras, buscando articulações discursivas que indiquem que essas cadeias discursivas são mutuamente constituídas e que o caráter político em sua radicalidade é dado pela contingência. Se ficarmos respondendo às convocações da responsabilização docente, operamos em lógicas estruturadas e com certa fixidez de sentidos dados pelos espaços tempos identitários como o bom/o mau aluno, a boa sociedade, as métricas classificatórias definidoras de posições fixas dos sujeitos.

Trata-se de uma tentativa de provocação "política" aos discursos da responsabilização docente calcados em perspectivas neoliberais, bem como ao discurso-denúncia que as perspectivas críticas fazem dessa lógica. Tentamos trazer à baila o discurso de que a responsabilidade, algo que assim possa ser chamado, deve passar pela indecidibilidade, pela prova da indecidibilidade: uma tomada de decisão que se dá na aporia, ainda que singular e também inscrita em uma tradição, uma presença na ausência, em um espaçotempo não localizável, visto o contingente e da ordem do acontecimento, da singularidade.

Travar esse debate em um campo contestado como o das políticas curriculares para a formação docente no momento atual, no qual as políticas reformadoras se fazem circular, nos parece inspirador na medida em que convoca a operar, nos dizeres derridianos - out of joint, fora dos eixos (Laclau, 2011b). A responsabilidade para que assim possa ser chamada opera disruptivamente, não é generalizável, é impossivel e necessária.

\section{Referências}

Afonso, A. J. (2009) Políticas avaliativas e accountability em educação: subsídios para um debate ibero-americano. Sísifo, Lisboa, n. 9, p. 57-69. 
Afonso, A. J. (2013) Mudanças no Estado-avaliador: comparativismo internacional e teoria da modernização revisitada. Revista Brasileira de Educação, Rio de Janeiro, RJ, v. 18, n. 53 , p. 267-284.

Afonso, A. J. (2014) Questões, objetos e perspectivas em avaliação. Avaliação, Campinas; Sorocaba, SP, v. 19, n. 2, p. 487-507.

Ball, S. J. (2004) Performatividade, privatização e o pós-Estado do bem-estar. Educação \& Sociedade, Campinas, SP, v. 25, n.89, p. 1105-1126.

Ball, S. J. (2010) Performatividade e fabricações na economia educacional: rumo a uma sociedade performativa. Educação \& Realidade. v. 2, n. 32, p. 37-55.

Ball, S. J. (2012) Reforma educacional como barbárie social: economismo e o fim da autenticidade. Práxis Educativa. v. 7, n. 1, p. 33-52.

Ball, S. J. (2014) Educação global S.A. Novas redes políticas e o imaginário neoliberal. Ponta Grossa, Editora UEPG: 2014. Cap 1: Redes Neoliberalismo e mobilidade das políticas.

Ball, S. J. (2009) A internacionalização das políticas educativas na América Latina. Currículo sem Fronteiras, v.9, n.2, pp.32-50.

Biesta, G. (2013) The beautiful risk of education. London: Paradigm.

Brooke, N. (2006) O futuro das políticas de responsabilização educacional no Brasil. Cadernos de Pesquisa, v. 36, n. 128, p. 377-401.

Brooke, N. (2008) Responsabilização educacional no Brasil. Revista Iberoamericana de Evaluación Educativa. v. 1, pp. 93-109.

Brooke, N. (2013) Controvérsias sobre políticas de alto impacto. Cadernos de Pesquisa, São Paulo: Fundação Carlos Chagas, v. 43, n. 148, p. 336-347.

Brown, W. (2015) Undoing demos. Brooklyn, New York: Zone BOOKS.

Clarke, M. (2015) Lacanian perspectives on education policy analysis. In: Kalervo, N. Gulson; Clarke, Mathew; Petersen, Eva Bendix. Education Policy and Contemporary Theory. London, Routledge. E-book.

Dias Sobrinho, J. (2003) Avaliação: políticas educacionais e reformas da educação superior. São Paulo: Cortez.

Derrida, J. (1994) Espectros de Marx: o estado da dívida, o trabalho do luto e a nova Internacional. Rio de Janeiro: Relume-Dumará. 
Derrida, J. (2006) Dar la muerte. Buenos Aires: Paidós/Surcos.

Freitas, L. C. de. (2012) Os reformadores empresariais da educação: da desmoralização do magistério à destruição do sistema público de educação. Educação \& Sociedade, Campinas, v. 33, n. 119, p. 379-404.

Freitas, L. C. de. (2013) Políticas de responsabilização: entre a falta de evidência e a ética. Cadernos de Pesquisa, São Paulo, v. 43, n. 148, p. 348-365.

Freitas, L. C. de. (2014) Os reformadores empresariais da educação e a disputa pelo controle do processo pedagógico na escola. Educação \& Sociedade, Campinas, v. 35. n 129, p. $1085-1114$.

Gimeno Sacristán, J. (1994) La Pedagogia por objetivos: obsesión por la eficiência. Madri: Morata.

Haddock-Lobo, R (2013). Notas sobre o trajeto aporético da noção de experiência no pensamento de Derrida. Educação e Filosofia. Uberlândia, v. 27, n. 53, p. 259-274.

Hargreaves, A. (1999) Profesorado, cultura y posmodernidad: cambian los tempos, cambia el professorado. Madrid: Edicionaes Morata.

Labaree, D. F. (1998). How to suceed in school without really learning. Yale: Yale University Press.

Laclau, E. (2006) Misticismo, retórica y política. Buenos Aires/México: Fondo de Cultura Económica.

Laclau, E. (2011a). Poder e representação. Emancipação e diferença; coordenação e revisão técnica geral, Alice Casimiro Lopes e Elizabeth Macedo. Rio de Janeiro: EdUERJ, p. 129-156.

Laclau, E. (2011b). O tempo está deslocado. Emancipação e diferença; coordenação e revisão técnica geral, Alice Casimiro Lopes e Elizabeth Macedo. Rio de Janeiro: EdUERJ, p. 107-128.

Laclau, E. (1990). New reflections on the Revolution of our Time. London: Verso.

Laclau, Ernesto; Mouffe, Chantal. (2011) Hegemonia e Estratégia Socialista. Buenos Aires: Fondo de Cultura Económica.

Lopes, A. C. (2006) Discursos nas políticas de currículo. Currículo sem Fronteiras, v. 6, p. 33-52. 
Lopes, A. C. (2014) Mantendo o conhecimento na conversação curricular, porém via discurso: um diálogo com Gert Biesta. Educação (PUCCamp), v. 19, p. 99-104.

Lopes, A. C. (2015) Por um currículo sem fundamentos. Linhas Críticas, Brasília, DF, v. 21, n. 45, p. 445-466, mai./ago. Disponível em: <http://periodicos.unb.br/index. php/linhascriticas/article/view/16735/11881>. Acesso em: 30 jan.

Lopes, A. C. (2018) Políticas de currículo em um enfoque discursivo: notas de pesquisa. In: Alice Casimiro Lopes; Anna Luiza Martins de Oliveira; Gustavo Gilson de Oliveira. (Org.). A Teoria do Discurso na Pesquisa em Educação. Recife: Editora da UFPE, v. 1, p. 133-167.

Lopes, A. C \& Borges, V. (2015) Formação docente, projeto impossível. Cadernos de Pesquisa (Fundação Carlos Chagas. Impresso), v. 45, p. 486-507.

Lopes, A. C. \& Macedo, E. (2011) Teorias de Currículo. São Paulo: Cortez.

Macedo, E. (2006) Currículo como espaço-tempo de fronteira cultural. Revista Brasileira de Educação, Rio de Janeiro, v.11, n. 32.

Macedo, E. (2015) Base Nacional Curricular Comum: a falsa oposição entre conhecimento para fazer algo e conhecimento em si. Texto apresentado no V SEB. Campinas: Cedes/Unicamp.

Mouffe, Chantal. On the political. London: Routledge, 2005.

MEC. (2015) Base Nacional Comum Curricular. Brasília: MEC/SEB.

MEC. (2014) Por uma política curricular para a educação básica. Brasília: MEC/SEB.

Oliveira, D. A. (2005) Regulação das políticas educacionais na América Latina e suas consequências para os trabalhadores docentes. Educação \& Sociedade, Campinas, v. 26, n. 92, p. 753-775.

Ravitch, D. (2011) Vida e morte do grande sistema escolar americano: como os testes padronizados e o modelo de mercado ameaçam a educação. Trad. de Marcelo Duarte. Porto Alegre: Sulina.

Santos, G. (2017) "O meu aluno não lê": sentidos de crise nas políticas curriculares para a formação em leitura. 232 f. Tese (Doutorado em Educação) - Programa de Pós-Graduação em Educação, Universidade do Estado do Rio de Janeiro, Rio de Janeiro.

Santos, G. \& Couto, B. (2018) A Proficiência em Alfabetização: contextualização sobre a Leitura, Escrita e Matemática a partir dos indicadores de larga escala. In.: 
Santos, G. et al. (2018) Processos de Alfabetização e o Sistema de Escrita Alfabética: aspectos e delineamentos que incidem na ação Didática. XIX Endipe, Salvador, Bahia.

Taubman, P.. (2009) Teaching by numbers: Deconstructing the discourse of standards and accountability in education. New York: Routledge.

\section{Biografia}

\section{Geniana dos Santos}

Coordenadora da Educação Infantil e Ensino Fundamental na Secretaria do Estado de Educação de Mato Grosso (SEDUC) e Docente no Centro Universitário de Várzea Grande (UNIVAG-MT).

Email: genianacba@gmail.com ORCID: https://orcid.org/0000-0001-6926-0132

\section{Veronica Borges de Oliveira}

Professora do Programa de Pós-graduação em Educação (ProPEd) da Universidade do Estado do Rio de Janeiro (UERJ).

Email: borges.veronica@gmail.com ORCID: https://orcid.org/0000-0002-00111769

\section{Alice Casimiro Lopes}

Professora do Programa de Pós-graduação em Educação (ProPEd) da Universidade do Estado do Rio de Janeiro (UERJ) e Procientista nesta mesma instituição. É Cientista do Nosso Estado Faperj e bolsista PQ 1B do CNPq.

Email: alicecasimirolopes@gmail.com ORCID: https://orcid.org/0000-0001-99439117 